Washington University School of Medicine Digital Commons@Becker

Open Access Publications

$5-18-2021$

\title{
Experience with liposomal amphotericin B in outpatient parenteral antimicrobial therapy
}

Yvonne J Burnett

Washington University School of Medicine in St. Louis

Andrej Spec

Washington University School of Medicine in St. Louis

Mohamed M Ahmed

Medical University of South Carolina

William G Powderly

Washington University School of Medicine in St. Louis

Yasir Hamad

Washington University School of Medicine in St. Louis

Follow this and additional works at: https://digitalcommons.wustl.edu/open_access_pubs

Please let us know how this document benefits you.

\section{Recommended Citation}

Burnett, Yvonne J; Spec, Andrej; Ahmed, Mohamed M; Powderly, William G; and Hamad, Yasir, "Experience with liposomal amphotericin B in outpatient parenteral antimicrobial therapy." Antimicrobial agents and chemotherapy. 65, 6. e01876-20 (2021).

https://digitalcommons.wustl.edu/open_access_pubs/10777

This Open Access Publication is brought to you for free and open access by Digital Commons@Becker. It has been accepted for inclusion in Open Access Publications by an authorized administrator of Digital Commons@Becker. For more information, please contact vanam@wustl.edu. 


\title{
Experience with Liposomal Amphotericin B in Outpatient Parenteral Antimicrobial Therapy
}

\author{
(D)Yvonne J. Burnett, ${ }^{a, b *}$ (D) Andrej Spec, ${ }^{b}$ Mohamed M. Ahmed, ${ }^{c}$ William G. Powderly, ${ }^{b}$ (D) Yasir Hamad \\ aDepartment of Pharmacy Practice, St. Louis College of Pharmacy at the University of Health Sciences and Pharmacy in St. Louis, St. Louis, Missouri, USA \\ bDivision of Infectious Diseases, Washington University School of Medicine in St. Louis, St. Louis, Missouri, USA \\ ‘Department of Nephrology, Medical University of South Carolina, Charleston, South Carolina, USA
}

ABSTRACT Outpatient parenteral antimicrobial therapy (OPAT) is a safe, effective, and convenient treatment strategy for patients receiving intravenous antimicrobials in the outpatient setting; however, data are limited describing the use and safety of liposomal amphotericin B (L-AMB). Records of patients receiving L-AMB OPAT between $1 / 1 / 2015$ and $7 / 31 / 2018$ were retrospectively reviewed. The primary objective was to describe the OPAT patient population discharged on L-AMB and evaluate factors associated with readmission and adverse events (AEs). Analysis was performed to evaluate for predictors of worse outcomes. Forty-two patients $(67 \%$ male, median age 50 years) were identified, most of whom were treated for histoplasmosis. The most common doses of L-AMB were $3 \mathrm{mg} / \mathrm{kg}(n=16,38 \%)$ or $5 \mathrm{mg} / \mathrm{kg}(n=14$, $33 \%)$ based on actual body weight. Twenty-six (62\%) patients completed their anticipated course of L-AMB. Twenty-two (52\%) patients were readmitted within 30 days of discharge; median time to readmission was 11 days (interquartile range [IQR] 5 to 18). While hypokalemia and acute kidney injury (AKI) were common, occurring in 26 $(62 \%)$ and $20(48 \%)$ patients, respectively, only 5 (12\%) were readmitted to the hospital due to L-AMB-associated AEs. Ninety percent of patients achieved at least partial renal recovery within 30 days after $L-A M B$ discontinuation. Factors significantly associated with AKI include higher L-AMB dose, lower serum potassium levels after therapy initiation, and receipt of potassium supplementation at discharge. L-AMB is associated with significant AEs; however, these results suggest that treatment is feasible in the outpatient setting with close monitoring, as the majority of AEs were managed effectively in an outpatient without long-term sequelae.

KEYWORDS amphotericin, OPAT, outpatient, nephrotoxicity, hypokalemia

utpatient parenteral antimicrobial therapy (OPAT) allows outpatient continuation of intravenous (IV) antimicrobials, reducing hospital length of stay and health care-associated costs while increasing patient satisfaction (1-3). However, OPAT is not without risks and complications. Decreased provider supervision increases risk of undetected and untreated adverse events (AEs). Additionally, implementation of OPAT programs assisting in transitions of care and monitoring is low (4-6).

Available OPAT data primarily report antibiotic outcomes, but information is lacking regarding amphotericin $B(A M B)$ for invasive fungal infections (IFIs) treatment. Patients with IFIs are often complex with significant comorbidities, like immune deficiency, malignancy, and transplant recipients, and frequently require prolonged durations of therapy (7-9). AMB remains the broadest spectrum systemic antifungal since its 1950s introduction and is often the most effective agent for many IFIs $(9,10)$. However, therapy is frequently limited by toxicity, including infusion reactions, electrolyte aberrations, and nephrotoxicity (10). Lipid formulations, now mainstays of therapy, are associated with less toxicity than that of conventional deoxycholate (11). Liposomal
Citation Burnett YJ, Spec A, Ahmed MM, Powderly WG, Hamad Y. 2021. Experience with liposomal amphotericin B in outpatient parenteral antimicrobial therapy. Antimicrob Agents Chemother 65:e01876-20. https://doi .org/10.1128/AAC.01876-20.

Copyright $\odot 2021$ American Society for Microbiology. All Rights Reserved. Address correspondence to Yvonne J. Burnett, Yvonne.burnett@uhsp.edu.

*Present address: Yvonne J. Burnett, Department of Pharmacy, Missouri Baptist Medical Center, St. Louis, Missouri, USA.

Received 4 September 2020 Returned for modification 3 November 2020 Accepted 21 March 2021

Accepted manuscript posted online 12 April 2021

Published 18 May 2021 
TABLE 1 Baseline and clinical characteristics ${ }^{a}$

\begin{tabular}{ll}
\hline & Median (IQR) or \\
Characteristic & $n(\%)$ (N=42) \\
\hline Age & $50(37-62)$ \\
Sex (Male) & $28(67)$ \\
& \\
Comorbidities & $19(45)$ \\
Malignancy & $3(7)$ \\
$\quad$ Solid tumor malignancy & $16(28)$ \\
$\quad$ Hematologic malignancy & $15(36)$ \\
Chemotherapy & $9(21)$ \\
Immunosuppressive medications (steroids, biologics, DMARDs) & $6(14)$ \\
Diabetes mellitus & $6(14)$ \\
Stem cell transplant recipients & $1(2)$ \\
Solid organ transplant recipients & $3(7)$ \\
Human immunodeficiency virus & \\
Site of infection & \\
Disseminated & $19(45)$ \\
Pulmonary & $11(26)$ \\
Central nervous system & $6(14)$ \\
Gastro-intestinal/abdominal organs & $4(10)$ \\
Sinusitis & $3(7)$ \\
Adrenal & $3(7)$ \\
Endocarditis & $2(5)$ \\
Candidemia & $2(5)$ \\
Osteomyelitis & $1(2)$ \\
Urinary tract & $1(2)$ \\
Type of fungal infection & \\
Histoplasmosis & \\
Aspergillus (including possible Aspergillus pneumonia) & $13(31)$ \\
Cryptococcus & $7(17)$ \\
Candida & $6(14)$ \\
Blastomyces & $5(12)$ \\
Mucorales & $3(7)$ \\
Others: Fusarium, Irpex lacteus, Rhodoturula, Ustilago, and possible & $2(5)$ \\
$\quad$ dematiaceous fungus & $5(12)$ (one patient [2\%] \\
\hline
\end{tabular}

${ }_{a} \mathrm{QR}$, interquartile range; DMARDs, disease modifying anti-rheumatoid drugs; HIV, human immunodeficiency virus.

amphotericin B (L-AMB) is the most widely used lipid formulation, but toxicity persists despite routine intensive monitoring, adding to the complexity of managing patients in less-supervised settings (11-16).

In the literature, AMB OPAT use is infrequent, ranging from 1 to $2 \%(2,4,12,17-22)$. Additionally, these studies include various $A M B$ products for both prophylactic and therapeutic indications. This study seeks to define patient populations receiving L-AMB OPAT for IFI treatment and determine rates and factors associated with readmission and $A E s$.

\section{RESULTS}

Forty-two patients received L-AMB OPAT between 01/01/2015 and 07/31/2018. Median age was 50 years (IQR 37 to 62 ) and 28 (67\%) were male. The most common comorbidities were malignancy, receipt of immunosuppressive agents, diabetes mellitus, and receipt of stem cell transplant, in 19 (45\%), 9 (21\%), 6 (14\%), and 6 (14\%) patients, respectively. Histoplasmosis was the most common indication (13 [31\%]), followed by aspergillosis (7 [26\%]) and cryptococcosis (6 [14\%]) (Table 1). Thirty-nine patients (93\%) initiated therapy during hospital admission, with median length of stay of 9 days (IQR 5 to 22) (Table 2), while three (7\%) started as outpatients. Most, 35 $(83 \%)$, were managed with home infusion pharmacy and nursing services, four at 
TABLE 2 Therapy characteristics and outcomes ${ }^{a}$

\begin{tabular}{|c|c|}
\hline Therapy characteristic or outcome & $\begin{array}{l}\text { Median (IQR) or } \\
n(\%)(\mathrm{N}=42)\end{array}$ \\
\hline Liposomal amphotericin B dose, $\mathrm{mg} / \mathrm{kg}$ & $4(3-5)$ \\
\hline \multicolumn{2}{|l|}{ Liposomal amphotericin B dose distribution } \\
\hline$<3 \mathrm{mg} / \mathrm{kg}$ & $3(7)$ \\
\hline $3 \mathrm{mg} / \mathrm{kg}$ & $16(38)$ \\
\hline $4 \mathrm{mg} / \mathrm{kg}$ & $7(17)$ \\
\hline $5 \mathrm{mg} / \mathrm{kg}$ & $14(33)$ \\
\hline$>5 \mathrm{mg} / \mathrm{kg}$ & $2(5)$ \\
\hline Index hospitalization length of stay (39 patients), days ${ }^{b}$ & $9(5-22)$ \\
\hline Hypokalemia during index admission ${ }^{b}$ & $25(64)$ \\
\hline Significant hypokalemia during index admission ${ }^{b}$ & $13(33)$ \\
\hline Nadir potassium during index admission ${ }^{b}$ & $3.1(2.8-3.5)$ \\
\hline Serum creatinine at discharge, $\mathrm{mg} / \mathrm{dl}$ & $0.9(0.7-1.1)$ \\
\hline Serum potassium value at discharge, $\mathrm{mmol} /$ liter & $3.8(3.5-3.9)$ \\
\hline Serum magnesium value at discharge, $\mathrm{mg} / \mathrm{dl}$ & $1.9(1.7-2)$ \\
\hline Concomitant nephrotoxic agent (vancomycin, tacrolimus) & $8(19)$ \\
\hline \multicolumn{2}{|l|}{ OPAT location } \\
\hline Home & $35(83)$ \\
\hline SNF/LTAC & $4(10)$ \\
\hline Infusion center & $2(7)$ \\
\hline \multicolumn{2}{|l|}{ OPAT clinical course } \\
\hline \multicolumn{2}{|l|}{ Duration } \\
\hline Planned length, days & $28(14-42)$ \\
\hline Actual total duration, including inpatient and outpatient (40 patients), days & $26(14-37)$ \\
\hline Outpatient duration of therapy, days & $14(10-26)$ \\
\hline Completion of L-AMB course fully as an outpatient & $23(55)$ \\
\hline $\begin{array}{l}\text { Median duration of therapy for those completing full course as an } \\
\text { outpatient, days }\end{array}$ & $18(14-30)$ \\
\hline Monitoring laboratory frequency, times per wk & $2(1-2.5)$ \\
\hline \multicolumn{2}{|l|}{ Renal toxicityc } \\
\hline Acute kidney injury & $20(48)$ \\
\hline Maximum serum creatinine after discharge, $\mathrm{mg} / \mathrm{dl}$ & $1.29(1-1.59)$ \\
\hline Time to acute kidney injury, days & $8.5(5-14)$ \\
\hline Patients received concomitant intravenous hydration with L-AMB & $21(50)$ \\
\hline \multicolumn{2}{|l|}{ Electrolyte management ${ }^{c}$} \\
\hline Hypokalemia ( $\mathrm{K}<3.5 \mathrm{mmol} /$ liter $)$ after discharge & $26(62)$ \\
\hline Severe hypokalemia ( $\mathrm{K}<3.0 \mathrm{mmol} /$ liter) after discharge & $16(38)$ \\
\hline Potassium supplement prescribed at discharge & $22(52)$ \\
\hline Nadir potassium after discharge, $\mathrm{mmol} / \mathrm{liter}$ & $3.1(2.8-3.7)$ \\
\hline Time to nadir hypokalemia, days & $7(4-9)$ \\
\hline Magnesium supplement prescribed at discharge & $12(29)$ \\
\hline Nadir magnesium after discharge, meq/liter & $1.6(1.5-1.9)$ \\
\hline \multicolumn{2}{|l|}{ Readmission } \\
\hline 30-day hospital readmission & $22(52)$ \\
\hline Time to readmission, days & $11(5-18)$ \\
\hline \multicolumn{2}{|l|}{ Reason for 30-day hospital readmission ( $\mathrm{N}=22$ [52\%]) } \\
\hline Adverse drug reaction & $5(12)$ \\
\hline Acute kidney injury & 3 \\
\hline Hypokalemia & 2 \\
\hline Worsening of infection & $3(7)$ \\
\hline $\begin{array}{l}\text { Other reasons, e.g., graft versus host disease, stem cell transplant, } \\
\text { Clostridioides difficile infection, bacterial sepsis }\end{array}$ & $14(33)$ \\
\hline
\end{tabular}

a $\mathrm{QR}$, interquartile range; L-AMB, liposomal amphotericin $\mathrm{B}$; ID, infectious diseases; OPAT, outpatient parenteral antimicrobial therapy; SNF, skilled nursing facility; LTAC, long-term acute care facility.

${ }^{b}$ Analysis included only those who were started during a hospitalization and did not include three patients started as an outpatient.

'When scored on the Naranjo scale, all cases met at least probable criteria due to temporal sequence, recognized $\mathrm{AEs}$, and improvement upon withdrawal (32). 


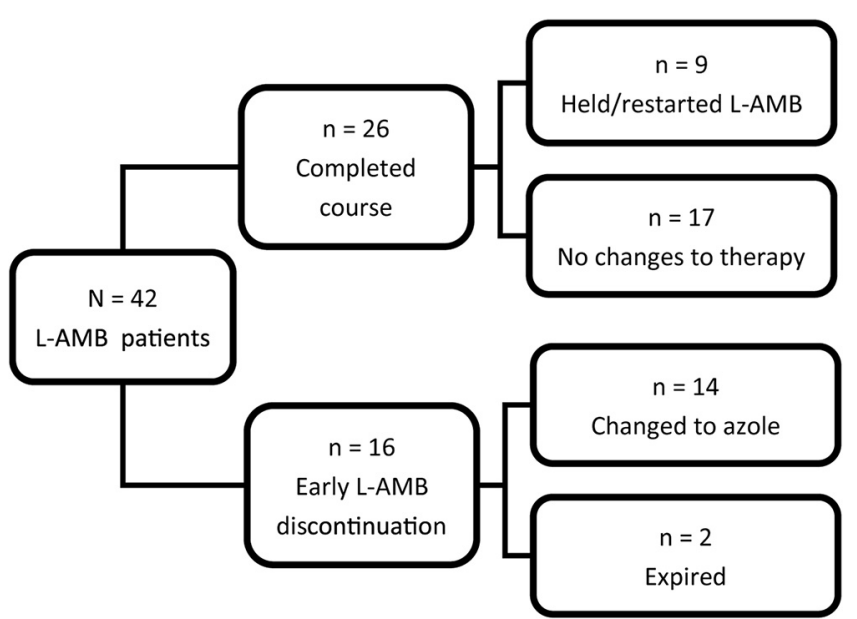

FIG 1 Outcomes of liposomal amphotericin B OPAT therapy.

postacute care facilities (PACFs), and two at infusion centers (Table 2). Labs were drawn a median of twice weekly (IQR 1 to 2.5). The most common L-AMB daily doses were 3 and $5 \mathrm{mg} / \mathrm{kg}, 16(38 \%)$ and $14(33 \%)$, respectively. Median total duration of therapy (inpatient and outpatient) was 26 days (IQR 14 to 37), and median OPAT duration was 14 days (IQR 10 to 26), resulting in 1,042 total OPAT days.

Twenty-two patients (52\%) were readmitted within 30 days, occurring at a median of 11 days (IQR 5 to 18) (Table 2). Five patients (12\%) were readmitted due to L-AMBassociated AEs (two for hypokalemia [serum potassium $\{\mathrm{K}\} 1.9$ and $2.4 \mathrm{mmol} / \mathrm{liter}$ ] and three for $\mathrm{AKI}$ ) and three (7\%) were readmitted due to worsening of IFI. Remaining readmissions, 14 (33\%), were due to factors unrelated to L-AMB or IFI. No factors were significantly associated with readmission; however, readmissions were numerically higher in patients with malignancy (13/22 [59\%] versus 6/20 [30\%], odds ratio [OR] 3.37, 95\% confidence interval [Cl] 0.94 to 12.11$)$.

Mortality occurred in two patients, both of whom developed AKI during therapy, due to progression of fungal disease (disseminated mold infection and resistant Candida glabrata candidemia).

Twenty-six (62\%) patients completed their anticipated L-AMB duration (Fig. 1). This included patients who were readmitted but for whom L-AMB continued as planned. Twenty-three (55\%) completed L-AMB as outpatients, with a median duration of 18 days (IQR 14 to 30 days) (Table 2). L-AMB was held in nine patients (21\%) for AE management but was resumed and courses were completed successfully. Of those with early L-AMB discontinuation, $88 \%$ switched to an azole antifungal. Four patients experienced infusion reactions, two with rigors or chills and one each with fever and anaphylaxis.

Upon L-AMB OPAT initiation, median serum creatinine ( $\mathrm{SCr}$ ) was $0.9 \mathrm{mg} / \mathrm{dl}$ (IQR 0.7 to 1.1); however, 20 patients (48\%) developed AKI at a median of 8.5 days (IQR 5 to 14$)$. This occurred despite $50 \%(n=21)$ receiving concurrent IV hydration. Factors associated with AKI (Table 3 ) included lower inpatient serum potassium after L-AMB initiation ( 3 versus $3.3 \mathrm{mmol} / \mathrm{liter}, P=0.04$ ), discharge prescription of potassium supplementation (70\% versus $36 \%$, OR $4.1,95 \% \mathrm{Cl} 1.1$ to 14.9 ), and higher L-AMB dose (4.6 versus $3.2 \mathrm{mg} / \mathrm{kg}, P=0.05$ ). Intravenous hydration was not associated with lower AKI risk (45\% versus 55\%, OR $0.7, \mathrm{Cl} 0.2$ to 2.3 ). No patients with AKI developed hyperkalemia, and median outpatient maximum potassium was $4.3 \mathrm{mmol} / \mathrm{liter}$ (IQR 2.9 to 5).

Of those who developed AKI, five (25\%) achieved full renal recovery within 30 days after discontinuation, while all surviving patients, 18 (90\%), experienced at least partial recovery. At 1 year postdiscontinuation, 13 (65\%) experienced full renal recovery at a median of 54 days (range 30 to 309). AKI management was 
TABLE 3 Factors associated with acute kidney injury (bivariate analysis) ${ }^{a}$

\begin{tabular}{|c|c|c|c|c|c|}
\hline Variable & $\begin{array}{l}\text { Acute kidney injury } \\
\text { median (IQR) or } n(\%) \\
(\mathrm{N}=20[48 \%])\end{array}$ & $\begin{array}{l}\text { No acute kidney injury } \\
\text { median (IQR) or } n(\%) \\
(\mathrm{N}=22[52 \%])\end{array}$ & $P$ value & $\begin{array}{l}\text { Odds } \\
\text { ratio }\end{array}$ & $\begin{array}{l}95 \% \\
\text { confidence } \\
\text { interval }\end{array}$ \\
\hline Age, yrs & $56(37-63)$ & $48(37-59)$ & 0.80 & & \\
\hline Diabetes mellitus & $4(20)$ & $2(9)$ & 0.40 & 2.5 & $0.4-15.4$ \\
\hline $\mathrm{L}-\mathrm{AMB}$ dose, $\mathrm{mg} / \mathrm{kg}$ & $4.6(3.3-5.1)$ & $3.2(3-4.4)$ & 0.05 & & \\
\hline Index hospitalization length of stay, days & $9(7-18)$ & $10(5-24)$ & 0.65 & & \\
\hline Patient received concomitant IV hydration & $9(45)$ & $12(55)$ & 0.54 & 0.7 & $0.2-2.3$ \\
\hline Concomitant nephrotoxic agent & $6(30)$ & $2(9)$ & 0.12 & 4.3 & $0.8-24.4$ \\
\hline Serum creatinine at hospital discharge, $\mathrm{mg} / \mathrm{dl}$ & $0.9(0.7-1.2)$ & $0.87(0.7-1)$ & 0.45 & & \\
\hline Peak serum creatinine, $\mathrm{mg} / \mathrm{dl}$ & $1.6(1.4-1.8)$ & $1(0.9-1.2)$ & NA & NA & \\
\hline Serum potassium at hospital discharge, $\mathrm{mmol} /$ liter & $3.8(3.5-3.9)$ & $3.8(3.5-3.9)$ & $>0.99$ & & \\
\hline Potassium supplementation prescribed at discharge & $14(70)$ & $8(36)$ & 0.03 & 4.1 & $1.1-14.9$ \\
\hline Nadir potassium level during index hospitalization & $3(2.7-3.2)$ & $3.3(3.1-3.8)$ & 0.04 & & \\
\hline Serum magnesium at hospital discharge, $\mathrm{mg} / \mathrm{dl}$ & $1.8(1.6-1.9)$ & $1.9(1.8-2)$ & 0.08 & & \\
\hline Magnesium supplementation prescribed at discharge & $7(35)$ & $5(23)$ & 0.50 & 1.8 & $0.5-7.1$ \\
\hline Nadir magnesium after discharge, $\mathrm{mg} / \mathrm{dl}$ & $1.6(1.3-1.7)$ & $1.8(1.6-2)$ & 0.06 & & \\
\hline
\end{tabular}

a $\mathrm{QQR}$, interquartile range; ID, infectious diseases; IV, intravenous; L-AMB, liposomal amphotericin B; NA, not applicable.

determined based on clinical judgment, resulting in 7 (35\%) conversions to azole antifungals; however, 13 continued L-AMB. Seven (35\%) were monitored and did not require therapy adjustment, 3 (15\%) adjusted frequency to $48 \mathrm{~h}$, and $1(5 \%)$ adjusted frequency to thrice weekly. No patient required hemodialysis due to L-AMB nephrotoxicity.

Potassium was within normal limits for over $75 \%$ of patients upon initiation of L-AMB OPAT; however, despite supplementation in 22 (52\%), 26 (62\%) developed hypokalemia, median nadir of $3.1 \mathrm{mmol} /$ liter (IQR 2.8 to 3.7). Sixteen (38\%) developed severe hypokalemia, associated with age (40 versus 59 years, $P=0.05$ ), L-AMB durations (30 versus 19.5 days, $P=0.02$ ), and nadir magnesium ( 1.5 versus $1.7 \mathrm{meq} / \mathrm{liter}$, $P=0.04)$.

\section{DISCUSSION}

To date, few reports detail L-AMB OPAT experiences $(12,21-23)$. This is the largest description of adult L-AMB OPAT patients, most of whom received daily infusions. We sought to determine rates and reasons for readmission and AEs to better understand this patient population and provide a description of L-AMB OPAT.

As expected with this complex population, readmission rates were high, occurring in $22(52 \%)$ patients. However, most readmissions were unrelated to L-AMB, 14 (33\%), with only 5 (12\%) due to L-AMB-associated AEs (3 AKI and 2 hypokalemia). No factors were significantly associated with readmission; however, patients with malignancy were more frequently readmitted. L-AMB-associated readmission rates are similar to those from a previous study of outpatient amphotericin (12\%); however, nonlipid AMB formulations were included in that study (12). In a study reporting thrice-weekly L-AMB OPAT, readmissions occurred in $22 \%$, but only one $(6 \%)$ readmission was attributed to L-AMB AKI (21). L-AMB-associated readmissions occurred in $17 \%(2 / 12)$ of patients in a study of antifungal OPAT that also utilized thrice-weekly administration (22).

High AE rates (20 to $72 \%$ ) associated with lipid formulations are most notably due to AKI, varying between 9 and 25\%, and electrolyte abnormalities (12-14). Compared to those in AMB deoxycholate, incidences of nephrotoxicity and infusion reactions are 
lower with L-AMB and other lipid formulations (14, 24). Previous data suggest that there may not be a strong association with $A E s$ and L-AMB dose; however, we noted an association with increased L-AMB dose and AKI (24-26). Most data regarding L$A M B$-associated AEs describe inpatients, but in one study evaluating outpatient $A M B$, nephrotoxicity occurred in $50 \%$ of adults (12).

Conflicting nephrotoxicity definitions are present in $A M B$ literature. These ranged from our definition, $0.5 \mathrm{mg} / \mathrm{dl}$ or $50 \%$ increase from baseline $\mathrm{SCr}$, to $\geq 1 \mathrm{mg} / \mathrm{dl}$ increase or doubling of baseline SCr $(11,12,14,21,24)$. As such, rates range from 10 to $56 \%$ depending on definitions used $(11,12,14,21,24)$. A more conservative definition was used in this study, reflecting clinical practice of our OPAT program.

Sodium loading has reduced nephrotoxicity in hospitalized patients receiving AMB deoxycholate $(12,27,28)$. Half of our patients received sodium loading via IV hydration with normal saline pre- and postinfusion upon OPAT initiation; however, this rose to $31(74 \%)$ after intervention by the OPAT team. This is consistent with sodium loading practices reported in a survey of inpatient clinical pharmacists regarding prophylactic strategies to prevent $A M B$ lipid formulation $A E s$, in which $68 \%$ reported routine use of IV fluid boluses (29), and similar to a previous report of community-based $A M B$, in which 50\% received sodium loading (12). Unlike AMB deoxycholate, a trend toward lower nephrotoxicity was not seen in patients who received sodium loading, and it is unclear whether this benefit exists for L-AMB, as studies have not assessed effect on lipid formulations. Conversely, excessive fluid loading may play a role in exacerbating potassium wasting in the setting of magnesium deficiency (30).

Previous studies reporting AMB OPAT found that high rates of nephrotoxicity occurred in older patients, those who had received a solid organ transplant, and those who were receiving concomitant cyclosporine (12). We observed an association with lower inpatient potassium levels and potassium supplementation on discharge. It is possible that hypokalemia is an early sign of L-AMB-induced nephrotoxicity. Magnesium deficiency may exacerbate hypokalemia and render it refractory to treatment by potassium replacement (30). As such, patients with magnesium deficiency may be unable to replete potassium stores with potassium supplementation alone.

While AKI occurred frequently, no patient required hemodialysis. Patients achieved full renal recovery after discontinuation up to a rate of $65 \%$, with $25 \%$ recovering within 30 days, similar to the results in prior reports (31). However, it should be noted for those with incomplete renal recovery that there may be implications affecting future therapy choices for underlying disease, emphasizing that L-AMB is not benign. While two patients died and experienced worsening renal function while on L-AMB, mortality was attributed to worsening infection. Inpatient management for patients at high risk for complications and those indicated for shorter courses may provide an opportunity for closer monitoring, allowing for earlier AE detection.

AEs were common, requiring close supervision by the OPAT team, which allowed for attentive and frequent laboratory monitoring, timely electrolyte replacement, and therapy adjustments. Over the last decade, OPAT team utilization has expanded, allowing for more comprehensive outpatient management. In a 2018 infectious diseases (ID) physician survey, 36\% reported OPAT program utilization, up from $26 \%$ in 2012 (5, 6). Despite increased OPAT programs, significant barriers to care still exist.

IDSA's 2018 Clinical Practice Guidelines for the Management of OPAT recommends at least twice-weekly monitoring of potassium and $\mathrm{SCr}$ and weekly liver function tests (LFT) and complete blood counts (CBC) for L-AMB (1). In a survey of OPAT practices among adult ID physicians, 415/450 responded regarding L-AMB monitoring frequency; $47 \%$ reported twice-weekly monitoring, followed by once- $(24 \%)$ and thriceweekly (22\%) monitoring (5). The Washington University School of Medicine (WUSM) ID OPAT team provides recommendations for thrice-weekly basic metabolic panels and once-weekly CBC and LFTs, guiding providers ordering laboratory studies on discharge. Despite this recommendation, we found that patients most often received twice-weekly studies (IQR 1 to 2.5). Patients with severe hypokalemia received more 
frequent monitoring, likely due to increased monitoring after supplementation and trending potassium losses. High-frequency monitoring may not be feasible for all situations, but we agree with at least twice-weekly laboratory monitoring.

Barriers to OPAT transitions of care include appropriate discharge ordering of laboratory studies, access to outpatient laboratory data, and communication between OPAT teams and patients or PACF (6). First-hand experience in management of this population reveals that while barriers may be overcome by a dedicated and efficient OPAT team, significant manpower is necessary to address these issues. Additionally, clear and efficient communication among team members and patients is paramount, due to frequent therapy adjustments to mitigate AEs. Appropriate patient selection, of stable patients in whom prolonged hospitalization may be detrimental, also aids in successful OPAT courses. Developing action plans in anticipation of AEs, such as thresholds for therapy adjustments or electrolyte replacement, allows for quick action from the OPAT team and decreases time to intervention. In review of these data, reduction in L-AMB frequency may be an effective management strategy given L-AMB's long half-life, as seen in a few recent reports (21-23).

Limitations are those inherent to retrospective studies, as data were collected from chart review and limited to provider documentation. While numbers were small, given the rarity of L-AMB OPAT, it is a relatively large study. The small sample size limits abilities to assess readmission and AE contributing factors, though some associations may be helpful when caring for this challenging patient population.

Strength of this study lies in examination of L-AMB OPAT in the current era of more prevalent OPAT programs. Few studies have evaluated outpatient AMB and included prolonged study periods (5 to 10 years) and multiple AMB formulations. This study is unique, as prophylactic dosing was excluded. Patients received higher and more frequent dosing than those on prophylaxis, allowing for inclusion of a population more likely to experience AEs. In addition, all patients in this study received L-AMB, while previous studies report on mixed use of $A M B$ deoxycholate and lipid formulations (12, 18-20). This study provided real-life experience with L-AMB OPAT, reporting clinically relevant outcomes, including readmission, significant hypokalemia, AKI, and associated factors.

Treatment with L-AMB OPAT is feasible but not without risks. With close monitoring and early intervention, OPAT teams can effectively manage a majority of L-AMB-associated AEs, without readmission or long-term sequelae. As OPAT programs continue to expand, additional work is needed to mitigate barriers to effective OPAT care, such as laboratory data access, correct discharge laboratory monitoring orders, and detecting transitions of care errors in these high-risk patients.

\section{MATERIALS AND METHODS}

This retrospective cohort consists of patients of $\geq 18$ years who were managed by Washington University School of Medicine (WUSM) in St. Louis, Division of Infectious Diseases (ID) OPAT team receiving outpatient L-AMB from 01/01/2015 to 07/31/2018. Only L-AMB treatments prescribed for therapeutic purposes were included, excluding lower prophylactic doses. The WUSM ID OPAT team, consisting of an ID physician and pharmacist, midlevel providers, and nurses, coordinates transitions of care, monitors laboratory results (at minimum once weekly), and cares for $>1,500$ patients annually. Patients were identified utilizing the OPAT database maintained by clinic nurses and ID pharmacist. Patients are referred to the OPAT team via ID consult during hospitalization at Barnes-Jewish Hospital, a 1,368-bed academic medical center, or outpatient referral. Patients received L-AMB at home with home infusion pharmacy and nursing, at postacute care facilities (PACF), or at outpatient infusion centers.

Data points were abstracted from the electronic medical record utilizing a standardized data collection form by two abstractors and included patient demographics, comorbidities, concomitant medications, laboratory data, IFI indication, L-AMB dosage, electrolyte supplementation, IV hydration, 30-day hospital readmission data, and reported AEs. Discrepancies were resolved by discussion with study investigators (Y. J. Burnett, Y. Hamad). Data were managed using REDCap (Research Electronic Data Capture), a secure, web-based application hosted by Washington University School of Medicine Institute for Informatics, Informatics Core Services. Deidentified data were downloaded and stored via a secure server for statistical analysis. The study was approved by the Human Research Protection Office at Washington University in St. Louis.

Study definitions include the following. Acute kidney injury (AKI): $0.5 \mathrm{mg} / \mathrm{dl}$ or $50 \%$ increase from baseline serum creatinine ( $\mathrm{SCr}$ ). Full renal recovery: return to $50 \%$ of baseline $\mathrm{SCr}$ at 30 days and 1 year 
after L-AMB discontinuation. Partial renal recovery: decrease by one stage of chronic kidney disease. Hypokalemia: $\mathrm{K}<3.5 \mathrm{mmol} /$ liter. Severe hypokalemia: $\mathrm{K}<3.0 \mathrm{mmol} /$ liter. Hypomagnesemia: $\mathrm{Mg}<1.5$ meq/liter. Infusion reactions: chills, fever, nausea, vomiting, dyspnea, chest pain, hypotension, and muscle spasm during or immediately following L-AMB infusion. AEs were classified in accordance with the Naranjo adverse drug reaction probability scale (32). Indication and planned duration of therapy were obtained from the ID provider note. For indefinite or long-term planned durations, 90 days was used as an estimate of how long patients may tolerate therapy.

Descriptive statistics analyzed baseline characteristics, care-related measures, and readmissions. Chisquare test analyzed categorical values, while Wilcoxon rank sum was used for continuous values. Odds ratios and $95 \%$ confidence intervals were calculated for categorical variables. Missing values were eliminated from analysis.

\section{ACKNOWLEDGMENTS}

The authors received no financial support for this research. Andrej Spec receives grant funding from Astellas and Mayne and performs advisory work for Scynexis, Minnetronix, and Viamet. Data were abstracted by Ara Gharabagi and Ciara Kellogg.

\section{REFERENCES}

1. Norris AH, Shrestha NK, Allison GM, Keller SC, Bhavan KP, Zurlo JJ, Hersh AL, Gorski LA, Bosso JA, Rathore MH, Arrieta A, Petrak RM, Shah A, Brown RB, Knight SL, Umscheid CA. 2019. 2018 IDSA clinical practice guideline for the management of outpatient parenteral antimicrobial therapy. Clin Infect Dis 68:e1-e35. https://doi.org/10.1093/cid/ciy745.

2. Hoffman-Terry ML, Fraimow HS, Fox TR, Swift BG, Wolf JE. 1999. Adverse effects of outpatient parenteral antibiotic therapy. Ann J Med 106:44-49. https://doi.org/10.1016/S0002-9343(98)00362-3.

3. Huang V, Ruhe JJ, Lerner P, Fedorenko M. 2018. Risk factors for readmission in patients discharged with outpatient parenteral antimicrobial therapy: a retrospective cohort study. BMC Pharmacol Toxicol 19:50. https:// doi.org/10.1186/s40360-018-0240-3.

4. Williams DN, Baker CA, Kind AC, Sannes MR. 2015. The history and evolution of outpatient parenteral antimicrobial therapy (OPAT). Int J Antimicrob Agents 46:307-312. https://doi.org/10.1016/j.jjantimicag.2015.07.001.

5. Lane MA, Marschall J, Beekmann SE, Polgreen PM, Banerjee R, Hersh AL, Babcock HM. 2014. Outpatient parenteral antimicrobial therapy (OPAT) practices among adult infectious diseases physicians. Infect Control Hosp Epidemiol 35:839-844. https://doi.org/10.1086/676859.

6. Hamad Y, Lane M, Beekmann S, Polgreen P, S Perspectives Of K. 2019. Perspectives of United States-based infectious diseases physicians on outpatient parenteral antimicrobial therapy practice. Open Forum Infect Dis 6: ofz363. https://doi.org/10.1093/ofid/ofz363.

7. Pappas PG, Kauffman CA, Andes DR, Clancy CJ, Marr KA, OstroskyZeichner L, Reboli AC, Schuster MG, Vazquez JA, Walsh TJ, Zaoutis TE, Sobel JD. 2016. Clinical practice guidelines for the management of candidiasis: 2016 update by the Infectious Diseases Society of America. Clin Infect Dis 62:e1-e50. https://doi.org/10.1093/cid/civ933.

8. Wheat LJ, Freifeld AG, Kleiman MB, Baddley JW, McKinsey DS, Loyd JE, Kauffman CA, Infectious Diseases Society of America. 2007. Clinical practice guidelines for the management of patients with histoplasmosis: 2007 update by the Infectious Diseases Society of America. Clin Infect Dis 45:807-825. https://doi.org/10.1086/521259.

9. Nett JE, Andes DR. 2016. Antifungal agents: spectrum of activity, pharmacology, and clinical indications. Infect Dis Clin North Am 30:51-83. https://doi.org/10.1016/j.idc.2015.10.012.

10. Dodds AE, Lewis R, Lewis JS, Martin C, Andes D. 2006. Pharmacology of systemic antifungal agents. Clin Infect Dis 43:S28-S39. https://doi.org/10 $.1086 / 504492$.

11. Safdar A, Ma J, Saliba F, Dupont B, Wingard JR, Hachem RY, Mattiuzzi GN, Chandrasekar PH, Kontoyiannis DP, Rolston KV, Walsh TJ, Champlin $\mathrm{RE}$, Raad II. 2010. Drug-induced nephrotoxicity caused by amphotericin B lipid complex and liposomal amphotericin B: a review and metanalysis. Medicine (Baltimore, MD) 89:236-244. https://doi.org/10.1097/MD .0b013e3181e9441b.

12. Malani PN, Depestel DD, Riddell J, Bickley S, Klein LR, Kauffman CA. 2005. Experience with community -based amphotericin B infusion therapy. Pharmacotherapy 25:690-607. https://doi.org/10.1592/phco .25.5.690.63591.

13. Steimbach LM, Tonin FS, Virtuoso S, Borba HHL, Sanches ACC, Wiens A, Fernandez-Llimós F, Pontarolo R. 2017. Efficacy and safety of amphotericin B lipid-based formulations-a systematic review and meta-analysis. Mycoses 60:146-154. https://doi.org/10.1111/myc.12585.

14. Wade RL, Chaudhari P, Natoli JL, Taylor RJ, Nathanson BH, Horn DL. 2013. Nephrotoxicity and other adverse events among inpatients receiving liposomal amphotericin B or amphotericin B lipid complex. Diagn Microbiol Infect Dis 76:361-367. https://doi.org/10.1016/j.diagmicrobio.2013.04.001.

15. Wingard JR, White MH, Anaissie E, Raffali J, Goodman J, Arrieta A. 2000. A randomized, double-blind comparative trial evaluating the safety of liposomal amphotericin B versus amphotericin B lipid complex in the empirical treatment of febrile neutropenia. L Amph/ABLC Collaborative Study Group. Clin Infect Dis 31:1115-1163. https://doi.org/10.1086/ 317451.

16. Falci DR, da Rosa FB, Pasqualotto AC. 2015. Comparison of nephrotoxicity associated to different lipid formulations of amphotericin B: a real-life study. Mycoses 58:104-112. https://doi.org/10.1111/myc.12283.

17. Rae N, Kenny C, Muldoon EG. 2019. Can intravenous antifungal therapy be safely used in the outpatient parenteral antimicrobial therapy (OPAT) setting? Mycoses 62:196-203. https://doi.org/10.1111/myc.12874.

18. Berman SJ, Johnson EW. 2001. Out-patient parenteral antibiotic therapy (OPAT): clinical outcomes and adverse events. Hawaii Med J 60:31-33.

19. Chapman ALN, Dixon S, Andrews D, Lillie PJ, Bazaz R, Patchett JD. 2009. Clinical efficacy and cost-effectiveness of outpatient parenteral antibiotic therapy (OPAT): a UK perspective. J Antimicrob Chemother 64:1316-1324. https://doi.org/10.1093/jac/dkp343.

20. Durojaiye OC, Bell H, Andrews D, Ntziora F, Cartwright K. 2018. Clinical efficacy, cost analysis and patient acceptability of outpatient parenteral antibiotic therapy (OPAT): a decade of Sheffield (UK) OPAT service. Int J Antimicrob Agents 51:26-32. https://doi.org/10.1016/j.ijantimicag.2017 .03.016.

21. van de Peppel RJ, Schauwvlieghe A, Van Daele R, Spriet I, van't Wout JW, Brüggemann RJ, Rijnders BJA, Hendriks BJC, de Boer MGJ. 2020. Outpatient parenteral antifungal therapy (OPAT) for invasive fungal infections with intermittent dosing of liposomal amphotericin B. Med Mycol 58:874-877. https://doi.org/10.1093/mmy/myz134.

22. Gil-Navarro MV, Luque-Marquez R, Báez-Gutiérrez N. 2020. Antifungal treatment administered in OPAT programs is a safe and effective option in selected patients. Enferm Infecc Microbiol Clin 38:479-484. https://doi .org/10.1016/j.eimc.2020.01.019.

23. Lewis PO, Khan I, Patel P. 2018. Successful stepdown treatment of pulmonary histoplasmosis with thrice-weekly liposomal amphotericin B in a hospital-associated outpatient infusion centre: a case report. J Clin Pharm Ther 43:269-272. https://doi.org/10.1111/jcpt.12609.

24. Groll AH, Rijnders BJ, Walsh TJ, Adler-Moore J, Lewis RE, Bruggemann RJM. 2019. Clinical pharmacokinetics, pharmacodynamics, safety and efficacy of liposomal amphotericin B. Clin Infect Dis 68:S260-S274. https:// doi.org/10.1093/cid/ciz076.

25. Walsh TJ, Yeldandi V, McEvoy M, Gonzalez C, Chanock S, Freifeld A, Seibel NI, Whitcomb PO, Jarosinski P, Boswell G, Bekersky I, Alak A, Buell D, Barret J, Wilson W. 1998. Safety, tolerance, and pharmacokinetics of a small unilamellar liposomal formulation of amphotericin B (AmBisome) in neutropenic patients. Antimicrob Agents Chemother 42:2391-2398. https://doi.org/10.1128/AAC.42.9.2391. 
26. Walsh TJ, Goodman JL, Pappas P, Bekersky I, Buell DN, Roden M, Barrett J, Anaissie EJ. 2001. Safety, tolerance, and pharmacokinetics of high-dose liposomal amphotericin B (AmBisome) in patients infected with Aspergillus species and other filamentous fungi: maximum tolerated dose study. Antimicrob Agents Chemother 45:3487-3496. https://doi.org/10.1128/ AAC.45.12.3487-3496.2001.

27. Branch RA. 1988. Prevention of amphotericin B-induced renal impairment: a review on the use of sodium supplementation. Arch Intern Med 148:2389-2394. https://doi.org/10.1001/archinte.1988.00380110049010.

28. Heidemann HT, Gerkens JF, Spickard WA, Jackson EK, Branch RA. 1983. Amphotericin B nephrotoxicity in humans decreased by salt repletion. Am J Med 75:476-481. https://doi.org/10.1016/0002-9343(83)90353-4.

29. Chastain DB, Giles RL, Bland CM, Franco-Paredes C, Henao-Martinez AF, Young HN. 2019. A clinical pharmacist survey of prophylactic strategies used to prevent adverse events of lipid-associated formulations of amphotericin B. Infect Dis (Lond) 51:380-383. https://doi.org/10.1080/ 23744235.2019.1568546.

30. Huang C, Kuo E. 2007. Mechanism of hypokalemia in magnesium deficiency. J Am Soc Nephrol 18:2649-2652. https://doi.org/10.1681/ASN 2007070792 .

31. Personett HA, Kayhart BM, Barreto EF, Tosh P, Dierkhising R, Mara K, Leung N. 2019. Renal recovery following liposomal amphotericin Binduced nephrotoxicity. Int J Nephrol 2019:1-8. https://doi.org/10.1155/ 2019/8629891.

32. Naranjo CA, Busto U, Sellers EM, Sandor P, Ruiz I, Roberts EA, Janecek E, Domecq C, Greenblatt DJ. 1981. A method for estimating the probability of adverse drug reactions. Clin Pharmacol Ther 30:239-245. https://doi .org/10.1038/clpt.1981.154. 